\title{
Studying the impact of mental health on job performance of managers and staff
}

\author{
Parviz Ahmadi $^{\mathrm{a}}$, Alireza Bakhshizadeh ${ }^{\mathrm{b}}$ and Hossein Balouchi ${ }^{\mathrm{c}}$
}

\author{
${ }^{a}$ Associate Professor in Management, Tarbiat Modarres University, Tehran, Iran \\ ${ }^{b}$ Master student in Commercial Management, Tarbiat Modarres University, Tehran, Iran \\ ${ }^{c}$ Master student in Commercial Management, University of Tehran, Tehran, Iran

A R T I C L E I N F O

Article history:

Received January 12, 2012

Received in Revised form

April, 26, 2012

Accepted 5 May 2012

Available online

May 72012

Keywords:

Health

Mental health

Job performance

Self-esteem

\section{Introduction}

Mental health plays an important role on increasing employee's productivity as well as efficiency. There are literally many different definitions for mental health case and world health organization (WHO) defines mental health as the capability of a balanced and harmonized relationship with others, to change and reform social and individual milieu, to resolve personal contrasts and tendencies rationally, fairly and properly. Levinson et al. (1962) defined mental health as the feelings of someone toward oneself, world, life location and surrounding people, our responsibility to others, how to cope the income and time/place recognition. According to Karl Menninger, mental health is someone's adaptation to his/her around world in the best possible choice so that it causes his/her happiness as well as a useful and efficient perception. There is another type of mental health care is domination and skillfulness in right contact to environment especially in three important issues of

\footnotetext{
* Corresponding author. Tel: +989132218436

E-mail addresses: abakhshizadeh@ymail.com (A. Bakhshizadeh)

(C) 2012 Growing Science Ltd. All rights reserved.

doi: $10.5267 / \mathrm{j} . \mathrm{ms} 1.2012 .05 .009$
} 
love, work and entertainment. Mental health care normally includes the talent to find a job, to have a family, to create a happy familial environment, to avoid any engagement in law and court, to enjoy life and to use the opportunities properly. According to WHO, approximately 10 to 15 percent of people in both developed and developing countries suffer from mental health issues and $14 \%$ of total global diseases are resulted from the lack of mental health. In USA, $14-20$ percent of children and adults suffer mental health disorders per annul, which shows the importance of mental health in current age in today's society, which is also an organizational society (Grady et al., 2011). In today's business circumstances, most part of individuals' times are devoted to organizations. Each organization satisfy general or special goals for the community and the people by conducting multiple or specialized tasks. Hence, life affairs now depend on organizations and social progress and survival depends on a function of the work and efficient performance. Through organizations, people do the jobs more efficiently and their performance influences on the quality of organizations' operations and social affairs (Alaghehband, 2004). Optimized usage of existing resources especially human resources in an organization is a common point among many managers who believe that the survival of an organization or institute depends on proper utilization of such resources. They also believe that an excellent workplace can increase employees' productivity.

The proposed study of this paper tries to perform an empirical study to measure the impact of mental health care on productivity. Performance appraisal is a process in which employees are evaluated in given intervals officially. Recognizing strong employees and giving awards to them as well as motivating them to improve their performance as well as the performance of other staff, inter alia, is the main reason for performance appraisal. In the past, traditional managers performed performance appraisal only to control employees' works. However, in today's studies, the focus is on more objectives that are more important. In fact, the ultimate goal of performance appraisal is to improve the efficiency and effectiveness of the organization rather than punishing weak staff.

\section{Literature review}

So far, studies on mental health are conducted in various settings including schools, universities, hospitals and other entities (Robson \& Haddad, 2011; Yearwood \& Siantz, 2010; Zachik et al., 2010; Lambert et al., 2004) but no study has addressed it in public companies and institutes. Due to progress and evolution of public and private entities, technologies and a vast range of intellectual and physical outcomes of such technologies, we need to have a deeper insight in scientific observations. There was another investigation on the impacts of principals' mental health on teachers at Tehran girl secondary schools and observed that managers with good mental health had higher and more satisfied performance while principals with poor mental health or neglect mental health principles consciously or unconsciously had lower and undesired performance. It was clarified in this research that there was a close positive relationship between principals' mental health and teachers' performance.

Gholtash et al. (2011) evaluated and compared the relationship between mental health and boy/girl athlete and non-athlete students' educational performance in secondary Schools at Marvdasht city, Iran. They investigated 100 athlete and 100 non-athlete students, randomly and reported that there was a significant difference between educational performance and mental health of athlete and nonathlete students. Besides, they concluded that there was no difference between the educational performance levels of athlete and non-athlete students. Likewise, they found that there was no difference between the mental health level of athlete and non-athlete students.

In research on studying and comparing mental health, progress motivation and educational performance among night/day students in Babol Industrial University located in north part of Iran, the author concluded that the rate of night students' mental health was more than day students in terms of such indicators as anxiety, depression, complaints and social actions. In the meantime, educational performance of day students was higher than night ones while their progress motivation was less than 
night students. In another study to investigate and compare employees' mental health and job burnout in Saipa Company, the second biggest auto maker in Iran, it was demonstrated that there was a significant relationship between white-collars' mental health compared with blue-collars and in terms of mental health, white - collars are in a better situation than blue-collars. Likewise, it was proved that there was a significant relationship between their mental health and job burnout namely more mental health, less job burnout and when mental health was more affected by various factors and job stress, job burnout were increased. In another research among girl and boy secondary students in Zahedan, the findings show that $42.78 \%$ of students suffer from anxiety as a mental health indicator. It was also observed that the relationship between examination anxiety and educational performance was significant but reversed.

In research conducted in Shahid Beheshti Medical University to study students' mental health and moderation methods among new students, the findings showed that people with more mental health had more problems solving capability and cognitive assessment. The author concluded that such people use more effective mediation methods, use more cognitive assessments and try to find solution. In a recent research, nurses' mental health was studied and it was concluded that nurses with low or very low mental health levels suffered from physical diseases, had lower discipline in their jobs, consumed more medicines, recourse to physicians further, had a chaotic sleep, were facing with contradictories between their life and job and experienced harder works compared with other nurses (Sveinsdóttir \& Gunnarsdóttir, 2008).

\subsection{Mental health in workplace}

Common turbulences and mental disease relate to low sleep, depression and anxiety are common in society and workplace. It is concluded in paramount studies that jobs with high hardness and depression had lower satisfaction level for employees (Lee et al., 2009). The main criterion for someone's mental health is that he/she can have harmonized interactions with his/her milieu. A healthy man is able to look for meeting his/her needs permanently and seeks in the environment. The collaboration between two critical elements is needed to achieve such aim: individual and environment. If we put aside the individual, what remains is environment. Therefore, there are various environments for one person such as family, school, workplace, residence location and so on. One can categorize the factors, which constitute the environment into two major groups: physical factors and human factors. Physical factors mean tools, machines, transportation vehicles, warmness/coldness equipment, security devices, workplace fuss, workplace air pollution and possible risks of working with cutting devices, etc. Human factors mean personality, attitude, perception, documents and conflicts between individuals and groups. Undoubtedly, both factors can impact on mental health positively or negatively. In fact, those employees who have problems for daily transportation to their work, have problems to be faced with lack of oxygen, to face with very low or very high temperature and so on. We are not planning to study the impacts of workplace physical aspects on mental health; rather, we are going to emphasize on human and mental aspects of workplace further. We only address to the impact of workplace fuss on mental health in order not to neglect the former and then we go to the impacts of human issues on mental health. It is proved that high fuss destroys some human hearing cells every day. An ambience with high fuss would produce stress and through headaches, stress would cause digestion system problems, abnormal fatigue, immunity system failure and heart diseases. Employees who work in such places are not interested in leaving their home, in entertainment, in going to parties or in inviting guests when they return from their workplace. In long term, other family members will feel tired of them. Those people who miss their audition can live hardly with family and others since they hear and interpret their words badly.

Working in condition that spatial noise is to $80 \mathrm{db}$ will never damage the ears even after 35 years. However, damages on audition are increasing when the noises are gradually growing. In $29 \%$ of 
cases, people who work in conditions with $100 \mathrm{db}$ for 35 years noise would suffer from irreversible lack of audition. If we look into other physical components in workplace carefully, we can observe that their mental impacts are not only less than fuss but also such impacts are further in some cases (Ganji, 2009). Therefore, discussing on all elements needs a separate research. As said, we put aside workplace physical or human elements. Initially, we explain personality and then we address to attitude, perception, document and conflict.

\subsection{Personality and behavior in work}

Personality consists of various aspects and one can consider a set of human behaviors centered on personality. Personality traits influence on behavior and psychologists implement some test to demonstrate such impacts. Here, we discuss on some traits that influence over organizational behavior or behavior in workplace (Ganji, 2009).

\subsubsection{Self - Esteem}

Self - esteem means the opinion of someone about himself/herself. It grows through a personal assessment on behaviors, appearance, intelligence, social success and also assessing other people. So opinions on one's good or bad behaviors, appearance ugliness or beautifulness, low or high intelligence and social successes and failures will be in a mutual conflict with others' behaviors, appearance, intelligence, successes and failures which shape our self - esteem. Overall, those who enjoy low self - esteem do not trust their talents and do not value them. Self - esteem impacts on the type of work someone tries to find. For instance, someone with high self - esteem risks highly in his/her job and looks for high levels in work hierarchy or looks for works that need high competition.

\subsubsection{Locus of control}

Locus of control means how much the person believes that he/she can impact his/her life and it can be internal or external. People with internal locus of control believe that they are the main makers of their lives while people with external locus of control believe that what happens is the result of chance, accident or the results of other people's performance. For instance, someone with internal locus of control accepts all responsibilities during a failure and believes that he/she is faulty while a person with external locus of control is more daring.

\subsubsection{Introversion and extraversion}

When we describe someone with introversion or extraversion traits, in fact, we are going to explain his/her behavioral method in social status. Extraversion is accompanied with clear verbal and nonverbal behaviors while introversion is accompanied with deficient and ashamed behaviors. Extravert people say their grievances to everyone, show everything they have in their mind, build social networks quickly. On the contrary, introvert people are self-possessed, do not disclose their secrets easily, do not establish social networks easily and cannot find many friends in their workplaces. It seems that it is better to use introvert people in jobs like the head of an auto-making factory, university management and management of associations. It is better to use introvert people in researches, laboratories, jobs, which require hardworking and concentration and miniature jobs. Introvert people are more successful in jobs that need high patience, care and thinking.

\subsubsection{Dogmatism}

A dogmatic man is someone who is inflexible in his/her opinions. This type of people accepts or rejects other people through some benchmarks that are not so different. They less effort to find 
information with lead into decision making since they do not look for the ideas of other people for decision making. Dogmatic people should decide alone. They work better in organized groups.

\subsubsection{Personal effectiveness}

Personal effectiveness occurs when a person trusts his/her skills and talents to perform a job. When such a person considers him/her in high level of personal effectiveness, he/she will equally believe that he/she has the necessary skills to be successful and he/she will be confident that can achieve the aims despite of barriers in the path.

\subsubsection{Need to power}

A person who needs power shows his/her inner tendency to impact and guide other people. Additionally, such people are interested in controlling their environment. Therefore, someone who needs power would show further propensity to political behaviors since such behaviors help him/her control the environment and others.

\subsubsection{Eagerness to risk}

Some people actively look for high-risk situations but others easily avoid jobs, which need risk and competition. It seems that risk-takers tend to act in political activities. However, since political activities do not necessarily lead to success generosity, the people who are not interested in taking much risk would avoid them. They will suffer from serious mental damages if they enter into political activities compulsorily.

\subsection{Attitude and behavior in work}

After mentioning personality as an affecting factor on personality, it should be interesting to study on the close relationship between personality and attitude since they are two major factors in workplace. Attitude means a positive or negative feeling to someone or something. When say that we do not like someone or something, in fact we expose our attitude. One should not forget that attitudes impact on behavior but they do not predict it necessarily. Here, three important attitudes are pointed based on their impacts on behavior in work.

\subsubsection{Job satisfaction}

One can say that job satisfaction means a positive emotional mood, which reflects employees' personal opinions on their work or workplace climate. Job satisfaction is relatively important for managers since the overall idea is that a satisfied worker or employees maintains a good return, does not absent, does not cause any accident, does not create any trouble, is happy and helps happiness in workplace. However, some people showed that this relationship was not so important. There is a direct relationship between performance in job and job dissatisfaction. Those employees who are dissatisfied with their jobs were more exposed by physical/mental or absenteeism syndromes. Therefore, measuring job satisfaction is especially important for managers and supervisors.

\subsubsection{Resemblance with organization}

This is a behavior in which a person considers organizational values as his/her own values and resembles it. There are two types of organizational resemblance, which influence employees' behaviors and they are affective and agreed resemblance. When someone is influenced by affective resemblance, he/she is interested in staying in organization since he/she is highly interested in organization. When someone is influenced by agreed resemblance, he/she stays in organization only 
because he/she cannot do any other job. People with high organizational resemblance perform their jobs with high quality, absent less and, more important, have more productivity.

\subsubsection{Conflict}

Conflict in organization means general, partial, real or sensational contradictories between roles, goals, purposes and interests of some people, groups or services. Conflict reflects such concepts as lack of understanding, dispute, difference and disagreement. Conflicts are created from interpersonal relationships and reflect the incompatible expectations of people or groups and the changes on their activities. Non-adoption of goals and methods, resource limitation, pressures of work emergencies and its outcomes are components that facilitate conflicts but managers must consider conflict as a reality. The aim is not to mobilize all forces to remove the conflict when the conflict is observed. Long term conflicts have serious mental and physical influences. Light mental disorders are, inter alia, mental impacts and physical impacts include stomach ulcer, nettle rash, constipation, headaches and so on.

\section{$2.4 \quad$ Research hypotheses}

According to above points and research conceptual method (Fig. 1), 8 hypotheses are considered as follow:

1. There is a significant relationship between employees' self - esteem and job performance.

2. There is a significant relationship between employees' locus of control and job performance.

3. There is a significant relationship between employees' depression/anxiety and job performance.

4. There is a significant relationship between employees' job satisfaction and job performance.

5. There is a significant relationship between employees' organizational resemblance and job performance.

6. There is a significant relationship between conflict and job performance.

7. There is a significant difference between job performance and mental health.

8. There is a significant difference between mental health and job performance of male and female staff.

\section{Research methodology}

As mentioned before, present study investigates the impacts of mental health on employees' job performance. Independent variable is employees' job performance. Our aim is to see that by changes in each employee's mental health rate (dependent variable), namely the score of each person from relevant questionnaire, how much this rate changes. As mentioned, dependent variable is employees' mental health rate in Fajr-e-Jam Refinery Company. Author aims to study changes in this index and the reflection of its feedback in independent variable.

Research methodology is correlative - type survey. Descriptive methodology includes all methods, which aim to interpret studied conditions or phenomena. Two questionnaires on mental health and job performance are used. In mental health questionnaire, one can find a combination of DASS-42 standard questionnaire items on depression and anxiety indices accompanied with questions on the indicators of self - esteem, locus of control, depression, anxiety, job satisfaction, resemblance with organization and conflict. According to indicators shown in research model (Fig. 1), job performance was devised. Research conceptual model can be outlined as follow.

Research population consists of all employees at Fajr-e-Jam Refinery in Jam city (Bushehr province). The statistical sample includes 42 employees (13 females and 29 males) selected by random sampling method. To determine the reliability and validity, Chronbach's alpha coefficients were computed for all items related to mental health and job performance variables. Such coefficients are shown for mental health variables and job performance variables in Table 2 and Table 3, respectively. 


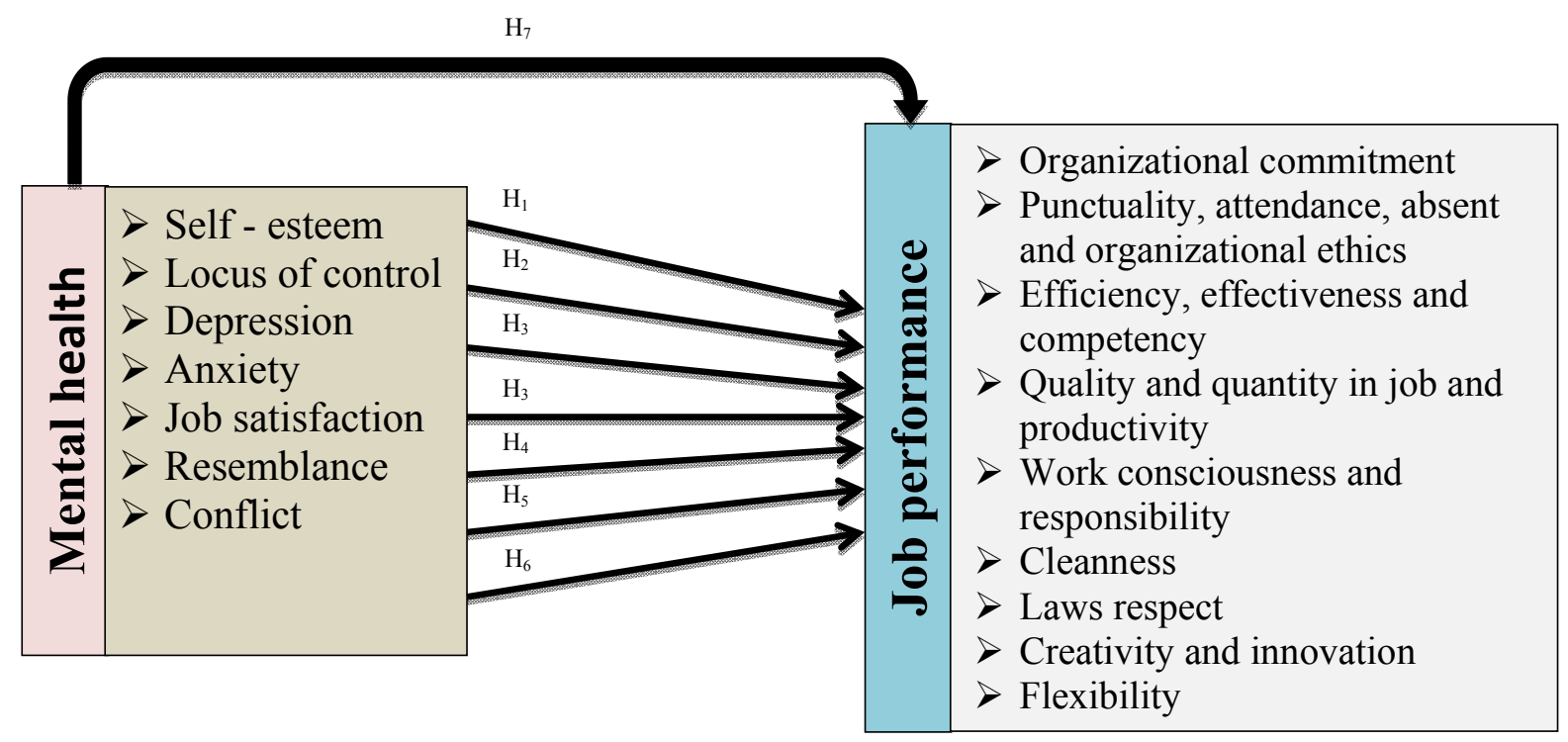

Table 2

Fig. 1. Research conceptual model

Chronbach's alpha coefficients for mental health variables

\begin{tabular}{llll}
\hline Variables & $\boldsymbol{\alpha}$ & Variables & $\boldsymbol{\alpha}$ \\
\hline Self - esteem & 0.697 & Job satisfaction & 0.909 \\
Locus of control & 0.744 & Organizational resemblance & 0.958 \\
Depression & 0.750 & Conflict & 0.762 \\
Anxiety & 0.753 & Total $\boldsymbol{\alpha}$ & $\mathbf{0 . 8 9 2}$ \\
\hline
\end{tabular}

Alpha rate is larger than 0.7 for all mental health variables and total alpha rate is 0.892 which is acceptable. So, one can conclude that the first measurement instrument ( $1^{\text {st }}$ questionnaire) enjoys good reliability.

Table 3

Chronbach's alpha coefficients for job performance variables

\begin{tabular}{llll}
\hline Variables & $\boldsymbol{\alpha}$ & Variables & $\boldsymbol{\alpha}$ \\
\hline Organizational commitment & 0.948 & Cleanness & 0.958 \\
Punctuality and organizational ethics & 0.952 & Laws respect & 0.951 \\
Efficiency, effectiveness and competency & 0.950 & Creativity and innovation & 0.953 \\
Quality and quantity in work and productivity & 0.957 & Flexibility & 0.944 \\
Work consciousness & 0.955 & Total $\boldsymbol{\alpha}$ & $\mathbf{0 . 8 9 2}$ \\
\hline
\end{tabular}

Alpha rate is larger than 0.0 for all job performance variables and total alpha rate is 0.892 , which is acceptable. So, one can conclude that the second measurement instrument ( $2^{\text {nd }}$ questionnaire) enjoys good reliability. This is descriptive - correlative research. T test, correlation test and variance equivalence test are used to analyze data. Correlation test is used to test hypotheses 1 to 7 . T test and variance equivalence test are applied to compare mental health among male and female staff.

\section{Testing hypotheses}

The results of correlation test for hypotheses 1 to 7 are depicted in Table 4 . 
Hypothesis 1: Based on the results of Table 4, Pearson's correlation coefficient between two self esteem and performance variables is 0.680 . Since significance error is zero $(\mathrm{sig}=0.000)$ and less than error estimation $(\alpha=0.05), \mathrm{H}_{0}$ is rejected and $\mathrm{H}_{1}$ is supported. Thus, one can conclude that more employees' self - esteem, more productivity.

Hypothesis 2: Based on the results of Table 4, Pearson's correlation coefficient between locus of control and performance variables is 0.676 . Since significance error is zero $(\operatorname{sig}=0.000)$ and less than error estimation $(\alpha=0.05), \mathrm{H}_{0}$ is rejected and $\mathrm{H}_{2}$ is supported. Thus, one can conclude that more employees' locus of control (i.e. they consider them as responsible to their own failures and successes and do not consider the failures as others faults), more efforts to arise job return.

Hypothesis 3: Based on the results of Table 4, Pearson's correlation coefficient between two depression and performance variables is -0.731 and Pearson's correlation coefficient between two anxiety and performance variables is -0.712 . Since significance error for both depression and anxiety is zero $(\mathrm{sig}=0.000)$ and less than error estimation $(\alpha=0.05), \mathrm{H}_{0}$ is rejected and $\mathrm{H}_{3}$ is supported. It means that both depression and anxiety have a reversed relation to job performance. Thus, one can conclude that more employees' depression and anxiety, less return compared to other people and vice versa.

Hypothesis 4: Based on the results of Table 4, Pearson's correlation coefficient between two job satisfaction and performance variables is 0.227 . Since significance error is $0.147(\mathrm{sig}=0.147)$ and larger than error estimation $(\alpha=0.05), \mathrm{H}_{0}$ is supported and $\mathrm{H}_{4}$ is rejected. It means that these two variables have no significant relationship.

Hypothesis 5: Pearson's correlation coefficient between two resemblance and performance variables is 0.428 . Since significance error is $0.005(\mathrm{sig}=0.000)$ and less than error estimation $(\alpha=0.05), \mathrm{H}_{0}$ is rejected and $\mathrm{H}_{51}$ is supported. It means that both variables have a significant reversed relationship. Thus, one can expect that more employees' efforts to adopt with their organizational aims would into more job performance.

Hypothesis 6: Pearson's correlation coefficient between two conflict and performance variables is 0.327 . Since significance error is $0.034(\mathrm{sig}=0.034)$ and less than error estimation $(\alpha=0.05), \mathrm{H}_{0}$ is rejected and $\mathrm{H}_{6}$ is supported. It means that both variables have a significant reversed relationship and the existence of conflict between the aims of employees and organization is a factor, which reduces their job performance. Thus, more employees' conflict leads into lower productivity.

Hypothesis 7: Pearson's correlation coefficient between two mental health and performance variables is 0.815 . Since significance error is zero $(\mathrm{sig}=0.000)$ and less than error estimation $(\alpha=0.05), \mathrm{H}_{0}$ is rejected and $\mathrm{H}_{7}$ is supported. It means that both variables have a significant reversed relationship. Thus, one can conclude that more employees' mental health would lead into more job performance.

Table 4

The results of hypotheses 1 to 7

\begin{tabular}{ccccccc}
\hline Hypothesis & \multicolumn{2}{c}{ Relationship } & Pearson Correlation coefficient & Sig & Result \\
\hline 1 & self - esteem $\longrightarrow$ & job performance & 0.680 & 0.000 & Supported \\
2 & locus of contrel $\longrightarrow$ & job performance & 0.676 & 0.000 & Supported \\
3 & Depression $\longrightarrow$ & job performance & -0.731 & 0.000 & Supported \\
4 & Anxiety $\longrightarrow$ & job performance & -0.712 & 0.000 & Supported \\
5 & Job satisfaction & job performance & 0.227 & 0.147 & Rejected \\
6 & Resemblance $\longrightarrow$ & job performance & 0.428 & 0.005 & Supported \\
7 & Conflict & job performance & -0.327 & 0.034 & Supported \\
8 & Mental health $\longrightarrow$ job performance & 0.815 & 0.000 & Supported \\
\hline$\alpha=0.05$ & & & & & &
\end{tabular}


According to Table 4, one can conclude that self - esteem, resemblance and mental health variables have a direct significant and depression, anxiety and conflict have a negative significant relationship with employees' job performance. Surprisingly, job satisfaction has no significant relationship with employees' job performance. The results of T test and variance equivalence test to compare mental health among female and male staff to test hypothesis 8 are outlined in Table 5.

Hypothesis 8: in t test, the assumption of averages equivalence and the contrary assumption is the existence of a significant difference between averages. In the case that significance error $(\mathrm{sig}=0.580)$ is larger than error estimation $(\alpha=0.05)$, then $\mathrm{H}_{0}$ is supported; otherwise $\mathrm{H}_{0}$ is rejected namely we confirm the contrary assumption which means the existence of a significant difference between both groups. Since significant level is greater than estimation error, $\mathrm{H}_{8}$ is rejected and one can conclude that there is no significant difference between mental health and male/female employees' job performance. In $\mathrm{F}$ test, since significance level $(\mathrm{sig}=0.344)$ is greater than estimation error $(0.05)$, $\mathrm{H}_{0}$ is supported and $\mathrm{H}_{8}$ is rejected, that is, there is no significant difference between male/female employees' mental health.

\section{Table 5}

T test and variance equivalence test for $\mathrm{H}_{8}$

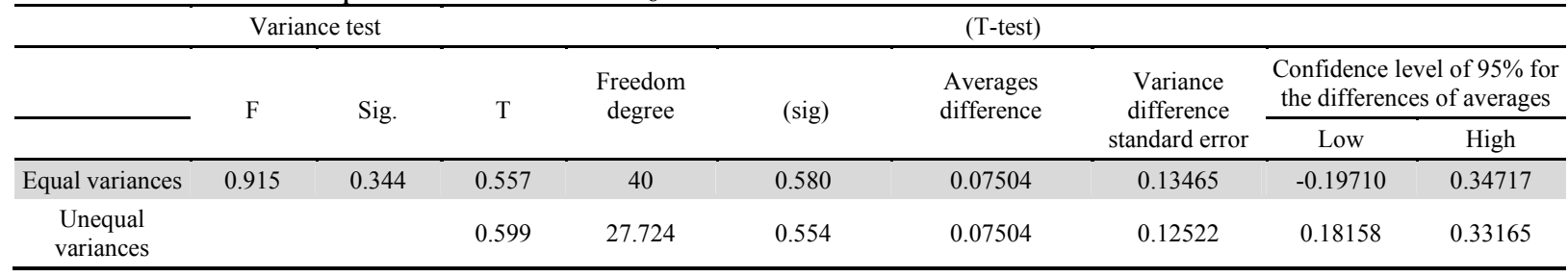

\section{Research Findings}

In present study, 42 male and female personnel were working in the company where $29(69 \%)$ and 13 (31\%) were male and female, respectively. 11 (26.2\%) were single and 30 (71.4\%) were married. Age range was 16 (38.1\%) under 30 year-old, 12 (28.6\%) between 30 - 40 and 14 (33.3\%) were between 40 - 50 year - old. In terms of education, $2(4.8 \%)$ had junior high school degree, 23 (54.8\%) had high school diploma, $14(33.3 \%)$ had B. A. and 3 did not answer this item. In terms of employment, $12(28.6 \%)$ were contractual staff, $23(54.8 \%)$ were official staff and $7(16.7 \%)$ had contracts. The average year of working in the company was 10.5 years.

Findings indicate that there was no significant relationship between gender and mental health and job performance. There is also no significant relationship between employees' education gender and mental health and job performance. It means that education and gender have no impact on employees' mental health and performance. There was a significant relationship between employees' job performance and mental health. All hypotheses were supported except the impact of job satisfaction on mental health and on job performance, which had no significant relationship.

\section{Conclusion}

The purpose of the present research was to study mental health and hob performance of employees' at Fajr-e-Jam Refinery Company. In paramount researches, it is depicted that the existence of mental disorders can reduce employees' job performance. A mental disorder like depression can be resulted from the lack of mental health in workplace. It poses heavy expenses on society and it leads into such costs as treatment costs or wasting job opportunities among other family members and the community. Thus, psychiatric diseases resulted for workplace stresses can mitigate the efficiency of workplaces. The main goal of this research was to determine the amount of employees' mental health and to compare it with their performance. The findings confirmed that there was a significant 
relationship between both variables and by comparing them it was analyzed that more employees' mental health, more their job performance and more affected employees mental health and an individual has lower mental health, his/her job performance will be decreased. The most important factor for development and advancement of any organization is to run its manpower. It seems that current conditions for the mental health of managers and employees should be considered as the most important aims and strategies of any organization. Concerning above points, one can perceive that by learning techniques to encounter stressing situations and preventing them in workplace, mental and spiritual health of people is initially assured and then the efficiency of workplace will be remarkably increased. There are various factors, which can face human mental health with problem. For example, workplace by impacting on stressor mechanisms and on health habits can affect on the possibility of suffering a disorder. Mainly, affecting factors on mental disorders are divided into two individual and spatial groups. Individual factors include heredity, gender, and physical power, individual differences in mental structure, interests and motivation. Spatial factors include physical and chemical factors, type and hour of work, structural changes, work manuals and policies, financial problems, job dissatisfaction, etc.

\section{References}

Alaghehband, A. (2004). General Management. Ravan Publications (In Farsi).

Allen, N. J., \& Meyer I.P. (1991). The measurement and antecedents of affective, continuance and normative commitment to the organization.

Gholtash, A., Moslem Salehi, S., Jahromi, A. \& Ostovari, A. (2011). Investigate and comparison of mental hygiene and educational performance of athletic and non-athletic high school students. Social and Behavioural Sciences, 80-83.

Grady, B.J., Lever, N., Cunningham, D., \& Stephan, S. (2011). Telepsychiatry and Telemental Health, 20(1), 81-94.

Lambert, A., Lambert, E., Itano, J., Inouy, J., Kim, S., Kuniviktikul, W., Sitthimongkol, Y., Pongthavornkamol, K., Gasemgitvattan, S., Ito, M., (2004). Cross cultural comparison of workplace stressors, ways of coping and demographic characteristics as predictors of physical and mental health among hospital nurses in Japan, Thailand, South Korea and the USA (Hawaii). International Journal of Nursing Studies, 41, 671-684.

Lee, M. S.-M., \& Lee, M.B., Liao, S.C., \& Chiang, F.T. (2009). Relationship between mental health and job satisfaction among employees in a medical center department of laboratory medicine. Formosan Medical Association, 108(2), 145-154.

Levinson, H., Price, C. R., Munden, K. J., \& Solley, C. M. (1962). Men, Management and Mental Health. Cambridge, MA: Harvard University Press.

Robbins, S.P. (2001). Organizational Behaviour. New Delhi, Prentice Hall, Inc.

Robson, D., \& Haddad, M. (2011). Mental health nurses' attitudes towards the physical health care of people with severe and enduring mental illness: The development of a measurement tool, International Journal of Nursing Studies, 49(1), 72-83.

Sveinsdóttir, H., \& Gunnarsdóttir, H.K. (2008). Predictors of self-assessed physical and mental health of Icelandic nurses: Results from a national survey. International Journal of Nursing Studies, $1479-1489$.

World Health Organization. (2005). The World Health Report 2005. Geneva, Switzerland: World Health Organization

Yearwood, L., Siantz, M., (2010). Global issues in mental health across the life span: Challenges and nursing opportunities. Nursing Clinics of North America, 45, 501-519.

Zachik, A., Naylor, W., \& Klaehn, L. (2010). Child and Adolescent Psychiatry Leadership in Public Mental Health, Child Welfare, and Developmental Disabilities Agencies. Child and Adolescent Psychiatric Clinics of North America, 19, 47-61. 